\title{
DIRETRIZES CURRICULARES DO CURSO DE PEDAGOGIA NO BRASIL: DISPUTAS DE PROJETOS NO CAMPO DA FORMAÇÃO DO PROFISSIONAL DA EDUCAÇĀO
}

\author{
Márcia Angela da S. Aguiar \\ IRIA BRZEZINSKI** \\ Helena Costa L. Freitas ${ }^{* * *}$ \\ Marcelo Soares Pereira da Silva ${ }^{* * *}$ \\ IVANY RODRIGUES PINO ${ }^{* * * * *}$
}

\begin{abstract}
RESUMO: Neste artigo, os autores analisam as novas diretrizes curriculares do curso de pedagogia, objeto de normatização do Conselho Nacional de Educação (CNE), em 2005, a partir do debate feito à luz do acervo de conhecimentos teórico-práticos sistematizados pelas principais entidades do campo educacional (ANFOPE, ANPED, CEDES, FORUMDIR, ANPAE). ${ }^{1}$ Evidenciam, criticamente, alguns dos problemas e das tensões que marcam a trajetória desse curso ao longo da história da educação brasileira. Focalizam, no âmbito das políticas educacionais, em especial, o movimento dos educadores pela definição das diretrizes curriculares para a formação dos profissionais da Educação Básica, que reflete posições de ordem epistemológica, pedagógica e política
\end{abstract}

* Professora da Universidade Federal de Pernambuco (UFPE) e atual presidente da Associação Nacional de Pós-Graduação e Pesquisa em Educação (ANPED).E-mail: marcia_angela@uol.com.br

** Professora da Universidade Católica de Goiás (UCG) e conselheira do Centro de Estudos Educação e Sociedade (CEDES). E-mail: iria@ucg.br

*** Professora aposentada da Universidade Estadual de Campinas (UNICAMP) e atual presidente da Associação Nacional pela Formação dos Profissionais da Educação (ANFOPE). E-mail: helena.freitas@uol.com.br

**** Professor da Universidade Federal de Uberlândia (UFU) e atual presidente do Fórum de Diretores de Faculdades/Centros de Educação das Universidades Públicas Brasileiras (FORUMDIR). E-mail: marcelosoares@ufu.br

****** Professora da Faculdade de Educação da Universidade Estadual de Campinas (UNICAMP) e atual presidente do Centro de Estudos Educação e Sociedade (CEDES).E-mail: ivany@unicamp.br

Educ. Soc., Campinas, vol. 27, n. 96 - Especial, p. 819-842, out. 2006

Disponível em <http://www.cedes.unicamp.br> 
Diretrizes curriculares do curso de pedagogia no Brasil...

atinentes às visões e aos projetos educacionais em disputa, no Brasil, nas últimas décadas. A problematização das diretrizes curriculares concorre para ampliar a compreensão da complexidade do campo da pedagogia e dos desafios teórico-práticos com que as instituiçôes de ensino superior, em particular as universidades, deparam-se para materializar a reforma do curso de pedagogia, na esteira das novas regulamentações legais e na perspectiva de uma formação cidadã.

Palavras-chave: Pedagogia e curso de pedagogia. Políticas educacionais. Diretrizes curriculares de pedagogia. Profissionais da educação. Formação de professores. Política de formação.

CuRriculum GUIDELINES OF THE PEDAGOGY COURSE IN BRAZIL:

PROJECT DISPUTES IN THE FIELD OF THE TRAINING OF EDUCATION PROFESSIONALS

ABSTRACT: Based on the debate conducted in the light of the theoretical-practical knowledge acquired by the main organisms of the educational field (ANFOPE, ANPED, CEDES, FORUMDIR, ANPAE), the authors analyze the new curriculum guidelines of the pedagogy course, which was regulated by the Conselho Nacional de Educação (CNE - Brazilian Council for Education) in 2005. They critically highlight some of the problems and tensions that have marked the trajectory of this course along the history of Brazilian education. Within the educational policies, they more particularly focus on the educator movement for the definition of curriculum guidelines for the training of basic education professionals, which reflects some epistemological, pedagogical and political positions related to the educational visions and project in dispute, in Brazil, these last decades. Problematizing the curriculum guidelines helps understanding better how complex the field of pedagogy is and what theoretical-practical challenges face the higher education institutions, more particularly universities, in order to concretize the reform of the pedagogy course to comply with the new legal regulations but also from the point of view of a citizen training.

Key words: Pedagogy and pedagogy course. Educational policies. Pedagogy curriculum guidelines. Education professionals. Teacher training. Training policies.

\section{Introdução}

7 esultam das diferentes interpretações do campo da pedagogia e 1 das disputas político-pedagógicas dos atores sociais, nos diversos contextos sócio-históricos, as várias identidades atribuídas ao cur- 
so de pedagogia, no Brasil. Essas identidades revelam, grosso modo, conflitos atinentes ao estatuto teórico e epistemológico da pedagogia e do curso de pedagogia, sobretudo no que se refere às concepções de licenciatura e bacharelado e seus desdobramentos na configuração curricular desse curso. Sem dúvida, as visões controvertidas a respeito dessas concepções têm predominado no debate e se manifestam mais claramente nas propostas que vinculam ou separam licenciatura e bacharelado, ora vistos como cursos distintos, ora como dimensōes de uma estrutura única de curso. ${ }^{2}$ Nos debates que pontuaram as duas últimas décadas, sobre as propostas de reformulaçôes curriculares do curso de pedagogia, essas posiçôes conflituosas se tornam mais visíveis nas proposições de diretrizes curriculares emanadas das comissóes de especialistas do curso de pedagogia $^{3}$ e em artigos sobre tal temática divulgados em livros e revistas de circulação nacional.

Como observam Aguiar e Melo (2005a), considerando as interpretaçôes diferenciadas sobre a pedagogia, as diversas identidades atribuídas ao curso de pedagogia no Brasil abrangem desde uma concepção de licenciatura separada do bacharelado, de corte positivista, a uma concepção de curso de estrutura única, envolvendo a relação intrínseca entre ambos, com base num enfoque globalizador.

Os diferentes sentidos dados historicamente à pedagogia e ao curso de pedagogia materializados no currículo expressam, como observam essas autoras, abordagens sobre teoria-prática, conteúdo-forma e objetosujeito e reportam-se às questôes epistemológicas e socioculturais que permeiam o debate sobre a modernidade. Hodiernamente, ainda se manifesta no campo teórico a visão tecnicista, sob a forma do neotecnicismo (Freitas, 1992; 1995), em confronto com outros enfoques tradicionais e críticos.

No plano da definição das políticas educacionais, em especial daquelas voltadas para a normatização das bases curriculares dos cursos de graduação, entre estes o de pedagogia, esses conflitos se expressam de forma permanente, traduzindo perspectivas diferenciadas dos atores envolvidos. Considerando tais tensões que atravessam as lutas sociopolíticas e a produção acadêmica da área, o presente texto (re)visita o curso de pedagogia, apontando para algumas questōes recorrentes ao longo de sua história, e que são (re)atualizadas no contexto político da reforma da educação superior no país, que se manifestam inclusive nas novas diretrizes curriculares do curso de pedagogia. 
Diretrizes curriculares do curso de pedagogia no Brasil...

A formação do educador no curso de pedagogia: os embates das últimas décadas

As políticas educacionais do regime autoritário monitoradas pelas Leis da Reforma Universitária (1968) e do Ensino de $1^{\circ}$ e $2^{\circ}$ Graus (1971), com evidente interesse de servir ao mercado, definiram um modelo de formação de professores compartimentado em dois loci da universidade: de um lado, a faculdade de educação ou unidade acadêmica equivalente, responsável pelo curso de pedagogia e a formação pedagógica dos licenciandos, e, de outro, os institutos de conteúdos específicos, onde se formavam bacharéis e licenciados.

Naquele contexto, as reformulações propostas para o curso de pedagogia encontram razões, especialmente, na indefinição dos conteúdos básicos do currículo, portanto na falta de especificidade do curso, pelo fato de a área de saber da pedagogia ser campo de aplicação de outras ciências, e no reducionismo simplista, manifestado no preceito legal de "treinar" pedagogos para desempenharem algumas tarefas não-docentes na escola.

A respeito do "treinar" pedagogos, Brzezinski (1994, p. 91) mostra desacordo ao assim expressar-se:

Essa prática autoritária, inculcadora de uma ideologia alienante que buscava transportar para a organização escolar, cuja natureza exige um trabalho coletivo, as relaçôes fragmentadoras, particularizadas inerentes às organizações do trabalho produtivo, dominou o sistema educacional brasileiro, por duas décadas. De maneira mais precisa, dominou a "capacitação de recursos humanos para a educação", a qual inclui formação de professores e especialistas, sob a égide da Teoria do Capital Humano.

Com base nestas "diretrizes" e na fundamentação doutrinária e técnica das duas leis já citadas, o CFE passou a elaborar indicações para definir "o papel e os campos de estudos próprios da Faculdade de Educação ou unidade equivalente" (Chagas, 1976, p. 9). Este autor, também idealizador e relator de um conjunto de indicaçōes no CFE, atribuía a ele a autoria de um novo "sistema de formação de professores" que deveria deitar por terra, de uma vez por todas, o Esquema 3+1. Seu intento, contudo, não foi alcançado, mas ele conseguiu aprovar no CFE um "pacote pedagógico", composto por diversas indicações que, não fosse a resistência dos educadores mobilizados nacionalmente, teria se consolidado como sistema. 
Nessa ocasião, a Valnir Chagas (1976) interessava provocar mudanças estruturais nas licenciaturas e propugnava a extinção do curso de pedagogia, quando aprovou no CFE as Indicações n. 67/68/1975 e n. 70/71/1976, que discorriam, respectivamente sobre Estudos Superiores de Educação, Formação Pedagógica das Licenciaturas, Preparo de Especialistas em Educação e Formação de Professores de Educação Especial. A Indicação n. 69/1976, que versava sobre Formação do Professor para os Anos Iniciais da Escolarização em Nível Superior, não foi homologada. Segundo a ideologia da época, o "pacote pedagógico" de Chagas referia-se à "Formação de Recursos Humanos da Educação", que incluía o preparo para as funções docentes e não-docentes da escola de $1^{\circ}$ e $2^{\circ}$ graus.

A homologação das quatro supramencionadas indicações foi recebida pelos educadores como mais uma arbitrariedade do poder que desconhecia práticas, pesquisas e estudos desenvolvidos pelos profissionais que se debruçavam sobre as questóes da formação em seu cotidiano. Rapidamente, a mobilização nacional para a reformulação dos cursos de pedagogia tomou impulso à medida que foram suscitados debates acerca do corpus doutrinário e técnico das indicações do CFE.

Ponto de partida da mobilização foi a realização do I Seminário de Educação Brasileira (1978) na Universidade Estadual de Campinas (UNICAMP), organizado com a objetivo de divulgar resultados da pesquisa "Análise do currículo e conteúdo programático dos cursos de pedagogia com vistas a propostas alternativas de reformulação", o qual se transformou em marco histórico no Movimento dos Educadores que aspirava subverter a tradicional ordem de "cima para baixo" nas decisões sobre as questões educacionais.

Dois anos após, a USP sediou a I Conferência Brasileira de Educação (CBE), também um grande movimento que teve como tônica os questionamentos contra as políticas educacionais da ditadura. Nessa CBE, ${ }^{4}$ em 2 de abril de 1980, foi instalado o Comitê Pró-Formação do Educador, que passou a funcionar na Universidade Federal de Goiás (UFG).

O Movimento dos Educadores toma vulto e demonstra sua força, como resistência ao poder instituído, durante toda a década de 1980, por meio de debates, embates e manifestações públicas por intermédio de ações sob o ponto de vista epistemológico, político e didático-pedagógico. Sob o enfoque epistemológico, as ações dos educado- 
Diretrizes curriculares do curso de pedagogia no Brasil...

res visavam à redefinição e à busca da identidade do curso de pedagogia no elenco dos cursos de formação de professores. Sob o ponto de vista político, em face do processo de "abertura democrática" os educadores acreditavam na transformação político-social da sociedade brasileira, historicamente necessária. "Movidos pela consciência coletiva, deflagraram a luta pela valorização do magistério, assim como por um profissionalismo que fora entorpecido pelo utilitarismo cego das políticas educacionais" (Brzezinski, 2005, p. 12). Sob a perspectiva didático-pedagógica pretendiam apresentar uma proposta nacional de mudanças estruturais no curso de pedagogia, que rompesse com a camisa-de-força imposta pelo currículo mínimo. Perspectiva logo redimensionada, visto que as mudanças deveriam abranger todo o "sistema de formação de professores", ao se considerar que a formação pedagógica do professor mantém sua base teórico-epistemológica no campo educacional e a base da identidade do profissional da educação encontra-se na docência: todos são professores (grifos nossos) (Comissão Nacional, 1983, p. 5).

A literatura da área evidencia os muitos avanços e conquistas que advieram desses embates enfrentados na década da "abertura democrática". No conjunto das conquistas, podem-se destacar, em especial, a aceitação da base comum nacional organizada em eixos curriculares que, com a evolução dos estudos epistemológicos, foram tomando a dimensão de "(...) princípios norteadores que fundamentam a base comum nacional e expressam a concepção sócio-histórica da educação construída na práxis educacional" (ANFOPE et al., 2005, p. 1); as reformulaçôes curriculares feitas pela maioria das universidades públicas e particulares (que não se pautam pela lógica do lucro), que adotaram a docência como base da identidade do curso de pedagogia e extinguiram as habilitações; a intensa produção científica dos educadores socializada em periódicos e livros e a permanente participação no Fórum em Defesa da Escola Pública.

\section{O movimento pela construção das diretrizes de formação}

O movimento de discussão e elaboração das diretrizes da pedagogia tem um marco importante em 1998, quando a Comissão de Especialistas de pedagogia, instituída para elaborar as diretrizes do curso, desencadeou amplo processo de discussão, em nível nacional, ouvindo as coordenações de curso e as entidades - ANFOPE, FORUMDIR, ANPAE, ANPED, 
CEDES, Executiva Nacional dos Estudantes de pedagogia. O resultado desse processo foi a elaboração do Documento das Diretrizes Curriculares do Curso de Pedagogia e seu encaminhamento ao CNE, em maio de $1999,{ }^{5}$ após uma grande pressão de todos esses segmentos junto à SESU e à Secretaria de Ensino Fundamental, do Ministério da Educação, que resistiam em enviá-las ao CNE, na tentativa de construir as diretrizes para o curso normal superior, criado pela LDB e prestes a ser regulamentado.

Seguido de um conjunto de assinaturas representativas dos diferentes segmentos, o documento foi encaminhado ao CNE e permaneceu, ao longo de oito anos, aguardando a definição e regulamentação de outros pontos ainda polêmicos com relação à formação, como o próprio curso normal superior, que até o momento não possui suas próprias diretrizes. ${ }^{6}$ Para a criação dos inúmeros cursos hoje existentes, foram elaborados pela Comissão de Ensino de Pedagogia e pela Comissão de Especialistas Formação de Professores, em 2001, os indicadores para autorização e reconhecimento.

Neste intervalo entre maio de 1999 e junho de 2004, as várias iniciativas do MEC com relação à formação de professores e ao próprio curso de pedagogia (Parecer da Câmara do Ensino Superior - CES n. 133/01, Resoluçóes n. 01 e 02/2002, que instituem Diretrizes para Formação de Professores) causaram mais transtornos do que encaminhamentos positivos para tais cursos, a tal ponto que hoje a diversidade de estruturas exigirá provavelmente do Poder Público um acompanhamento rigoroso, bem como processos de avaliação da formação oferecida, de modo que se preservem as iniciativas positivas e se estabeleçam metas para o aprimoramento da qualidade de outras.

As iniciativas do MEC induziram também a uma política de crescimento desordenado do ensino superior privado. Cabe destacar a crescente expansão dos cursos normais superiores e do próprio curso de pedagogia, principalmente em instituições privadas, em sua grande maioria sem história e sem compromisso anterior com a formação em quaisquer de seus níveis e modalidades. Dados oficiais do INEP/MEC (2006) revelam que existem na atualidade 1.437 cursos de pedagogia e 1.108 cursos normais superiores, sem considerar os inúmeros ISEs e cursos de licenciatura criados também nesse período.

Os educadores e suas entidades acompanharam de perto este movimento, e estiveram presentes, em todo este período, mobilizando-se 
Diretrizes curriculares do curso de pedagogia no Brasil...

por meio de encontros, reuniōes, documentos, orientados sempre pelo princípio fundamental que desde a promulgação da LDB se firmara junto ao MEC, SESU e CNE: as discussóes das diretrizes da pedagogia se inserem na discussão das orientaçōes, politicas e Diretrizes da Formação dos Educadores da Educação Básica, não podendo, portanto, serem aprovadas fora deste contexto. Esta formulação corresponde a uma expectativa histórica dos educadores de construir uma política nacional de formação e, em seu interior, um sistema articulado e integrado de formação dos profissionais da educação, contemplando todas as modalidades e os níveis até a pós-graduação e a formação continuada. É indicadora ainda da compreensão de que essa formação somente atingirá níveis qualitativamente elevados se desenvolvida de forma integrada e articulada para todos os níveis de ensino, nas instituições universitárias.

Nessa direção, a ANFOPE, em documento de 1998, reafirma, com clareza, seus princípios ao indicar as diretrizes para a formação dos profissionais da educação:

A ANFOPE reafirma ainda que as Universidades e suas Faculdades/Centros de Educação constituem-se o lócus privilegiado da formação dos profissionais da educação para atuação na educação básica e superior. Reafirma também a necessidade de repensar as estruturas das Faculdades/Centros de Educação e a organização dos cursos de formação em seu interior, no sentido de superar a fragmentação entre as Habilitaçóes no curso de pedagogia e a dicotomia entre a formação dos pedagogos e dos demais licenciandos, considerando-se a docência como a base da identidade profissional de todos os profissionais da educação. (ANFOPE, 1998)

No período em foco, várias discussões ocorreram e documentos foram organizados com o objetivo de interferir na política de formação dos educadores. Em decorrência das pressôes das entidades, em junho de 1999, a SESU/MEC institui o GT Licenciaturas, composto por educadores da área e pela ANFOPE, que após amplas discussōes, tanto nas reuniôes da ANPED como no Congresso Estadual Paulista de Formação do Educador, ${ }^{7}$ elaborou o Documento Norteador para Elaboração das Diretrizes Curriculares para os Cursos de Formação de Professores. ${ }^{8}$ Esse documento chegou a ser discutido com representantes das entidades das áreas específicas das licenciaturas, em um processo que começava a romper as resistências, mas foi "engavetado" pelo MEC, que decidiu elaborar outro documento enviado ao CNE, o qual foi aprovado em 2001 e 2002 
como as Diretrizes para os Cursos de Formação Inicial de Professores para a Educação Básica. ${ }^{9}$ Já naquele momento, a ANFOpE e a Comissão de Especialistas de pedagogia, da SESU/MEC, apontavam com clareza a necessidade de tratar, simultaneamente e de forma integrada, a formação de todos os profissionais da educação, licenciados e pedagogos. A recusa do MEC foi sempre uma tônica desses debates e embates.

Em agosto de 1999, a ANFOPE manifestava-se firmemente com relação a essa reivindicação junto ao CNE e ao MEC. Em novembro desse ano, durante o IV Seminário Nacional e o I Encontro Nacional dos Fóruns de Licenciaturas, realizados conjuntamente, em Recife, pela ANFOPE e FORUMDIR, ocorreu a recusa à proposta da conselheira Eunice Durhan (do $\mathrm{CNE}$ ), que pretendia eliminar a possibilidade de formação de docentes para as séries iniciais e educação infantil dos cursos de pedagogia (cf. Carta de Recife, ANFOPE/FORUMDIR, 5/11/1999).

Logo após, em dezembro de 1999, é desencadeada uma ampla mobilização nacional contra o Decreto n. 3.276/99, que estabeleceu a exclusividade dos cursos normais superiores para a formação dos professores para esses níveis de ensino. O conteúdo desse decreto, em razão de pressão das universidades e entidades dos educadores com relação ao governo federal, foi alterado em 2000 mediante o Decreto n. 3.554, que substituiu o termo preferencialmente no lugar do exclusivamente. ${ }^{10}$

Em maio de 2000, anterior à realização do X Encontro Nacional de Didática e Prática de Ensino (ENDIPE), acontece o V Seminário Nacional da ANFOPE e FORUMdir e o II Encontro Nacional dos Fóruns das Licenciaturas, com posicionamentos sobre a aludida questão. $\mathrm{Na}$ 52a Reunião Anual da SBPC, em Brasília, em julho de 2000, a Carta do Fórum Nacional em Defesa da Escola Pública, firmada por 12 associações e fóruns de educadores, reafirma a necessidade de manter, nos cursos de graduação plena, pedagogia, a formação de professores para as séries iniciais e educação infantil, entre outros temas.

Durante as audiências públicas regionais e nacional do CNE, que se sucederam entre fevereiro e abril, para discussão das diretrizes de formação de professores, as entidades signatárias - ANPED, ANFOPE, ANPAE e FORUMDIR - reafirmam novamente, em cuidadosos e extensos documentos, a necessidade do estabelecimento de diretrizes nacionais específicas para os cursos de pedagogia, considerando a proposta da Comissão de Especialistas de Ensino de Pedagogia de 1999. 
Diretrizes curriculares do curso de pedagogia no Brasil...

Durante consulta ao setor acadêmico, no âmbito do programa especial do CNE "Mobilização Nacional por uma Nova Educação Básica", em 7 de novembro 2001, novamente as entidades da área apresentam ao CNE o documento Posicionamento Conjunto das Entidades, reafirmando as diretrizes curriculares para o curso de pedagogia, que aprofunda e explicita as diretrizes de 1999 .

Esse documento serviria de base para a Proposta de Diretrizes Curriculares Nacionais para o Curso de Graduação em Pedagogia, ${ }^{11}$ elaborada pela Comissão de Especialistas de Pedagogia e pela Comissão de Especialistas de Formação de Professores, e enviada ao CNE em abril de 2002.

Em maio de 2002, são aprovadas as Diretrizes para Formação de Professores. Em junho de 2002, o CNE constitui Comissão Bicameral com a finalidade de estabelecer diretrizes operacionais para a formação de professores para a Educação Básica e apresentar estudo sobre a revisão das Resoluçôes CNE/CP n. 02/97, que dispõe sobre os programas especiais de complementação pedagógica de bacharéis, e CNE/CP n. 01/99, que dispõe sobre os institutos superiores de educação.

No contexto da disputa eleitoral, essa Resolução passa despercebida pela área e, mesmo após uma reunião ampla convocada durante a Reunião Anual da ANPED, em razão dos rumores da existência de $\mathrm{Mi}$ nuta de Resolução alterando os cursos de pedagogia, o seu conteúdo não foi socializado naquele momento.

No entanto, no antigo CNE novos movimentos vão se gestando com o fim de assegurar as mudanças que alguns setores propugnavam para o campo da formação. Vem, do Conselho Estadual de São Paulo, o "modelo" de estrutura dos cursos de formação. Nesse estado é gestada a idéia ${ }^{12}$ que se materializaria, posteriormente, no âmbito da Comissão Bicameral, na Minuta de Resolução, somente divulgada publicamente em julho de 2003, durante o Congresso Estadual Paulista de Formação do Educador, mobilizando as entidades para ampliar o debate, que vem a acontecer em outubro, durante a reunião da ANPED.

Novas diretrizes curriculares do curso de pedagogia e as proposições das entidades do campo educacional

As Diretrizes Curriculares Nacionais para o Curso de Pedagogia, consubstanciadas nos Pareceres CNE/CP n. 05/2005, 01/2006 e na Resolução CNE/CP n. 01/2006, demarcam novo tempo e apontam para no- 
vos debates no campo da formação do profissional da educação no curso de pedagogia, na perspectiva de se aprofundar e consolidar sempre mais as discussōes e reflexões em torno desse campo.

Esse aprofundamento exige, no entanto, que se delineiem de forma mais clara e precisa os contornos e as perspectivas que essa formação poderá assumir em decorrência das diretrizes aprovadas.

As DCN-Pedagogia definem a sua destinação, sua aplicação e a abrangência da formação a ser desenvolvida nesse curso. Aplicam-se: a) à formação inicial para o exercício da docência na educação infantil e nos anos iniciais do ensino fundamental; b) aos cursos de ensino médio de modalidade normal e em cursos de educação profissional; c) na área de serviços e apoio escolar; d) em outras áreas nas quais sejam previstos conhecimentos pedagógicos. A formação assim definida abrangerá, integradamente à docência, a participação da gestão e avaliação de sistemas e instituições de ensino em geral, a elaboração, a execução, o acompanhamento de programas e as atividades educativas (Parecer CNE/CP n. 05/2005, p. 6).

Abre-se, assim, amplo horizonte para a formação e atuação profissional dos pedagogos. Tal perspectiva é reforçada nos artigos $4^{\circ}$ e $5^{\circ}$ da Resolução CNE/CP n. 01/2006, que definem a finalidade do curso de pedagogia e as aptidóes requeridas do profissional desse curso:

Art. $4^{\mathrm{o}}$ - O curso de Licenciatura em pedagogia destina-se à formação de professores para exercer funções de magistério na Educação Infantil e nos anos iniciais do Ensino Fundamental, nos cursos de Ensino Médio, na modalidade Normal, de Educação Profissional, na área de serviços e apoio escolar e em outras áreas nas quais sejam previstos conhecimentos pedagógicos.

Parágrafo único. As atividades docentes também compreendem participação na organização e gestão de sistemas e instituições de ensino, englobando:

I - planejamento, execução, coordenação, acompanhamento e avaliação de tarefas próprias do setor da Educação;

II - planejamento, execução, coordenação, acompanhamento e avaliação de projetos e experiências educativas não-escolares;

III - produção e difusão do conhecimento científico-tecnológico do campo educacional, em contextos escolares e não-escolares.

Delineia-se, pois, que a formação no curso de pedagogia deverá assegurar a articulação entre a docência, a gestão educacional e a produção do conhecimento na área da educação. Com essa explicitação, o legisla- 
Diretrizes curriculares do curso de pedagogia no Brasil...

dor afasta a possibilidade de redução do curso a uma formação restrita à docência das séries iniciais do ensino fundamental, aproximando-se, dessa forma, das propostas de diretrizes apresentadas pela Comissão de Especialistas de Pedagogia de 1999. Todavia, faz-se necessário demarcar a compreensão desses elementos constitutivos da formação do pedagogo.

A docência nas DCN-Pedagogia não é entendida no sentido restrito do ato de ministrar aulas. O sentido da docência é ampliado, uma vez que se articula à idéia de trabalho pedagógico, a ser desenvolvido em espaços escolares e não-escolares, assim sintetizado no Parecer CNE/CP n. 05/ 2005 (p. 7):

Entende-se que a formação do licenciado em pedagogia fundamenta-se no trabalho pedagógico realizado em espaços escolares e não-escolares, que tem a docência como base. Nesta perspectiva, a docência é compreendida como ação educativa e processo pedagógico metódico e intencional, construído em relações sociais, étnico-raciais e produtivas, as quais influenciam conceitos, princípios e objetivos da pedagogia.

Dessa forma, a docência, tanto em processos educativos escolares como nãoescolares, não se confunde com a utilização de métodos e técnicas pretensamente pedagógicos, descolados de realidades históricas específicas. Constitui-se na confluência de conhecimentos oriundos de diferentes tradições culturais e das ciências, bem como de valores, posturas e atitudes éticas, de manifestações estéticas, lúdicas, laborais. (Parecer CNE/CP n. 05/2005, p. 7)

Tomados sob essa perspectiva o trabalho docente e a docência implicam uma articulação com o contexto mais amplo, com os processos pedagógicos e os espaços educativos em que se desenvolvem, assim como demandam a capacidade de reflexão crítica da realidade em que se situam. Com efeito, as práticas educativas definem-se e realizam-se mediadas pelas relações socioculturais, políticas e econômicas do contexto em que se constroem e reconstroem. Nessa perspectiva, Aguiar e Melo (2005a) afirmam:

(...) escapando aos reducionismos da visão teoricista (aplicação instrumental da teoria na prática), e do praticismo (prioridade ao saber tácito, construído na prática imediata cotidiana) na sala de aula, tem-se o entendimento de que a docência é o fulcro de articulação dos diversos conhecimentos - aportes teóricos da pedagogia e das Ciências da Educação e de outros conhecimentos especializados e daqueles produtos das práticas escolares e não-escolares refletidas. Lugares onde ela se (re)produz interna- 
mente nas suas especificidades, construindo novas alternativas de práticas pedagógicas diante de problemáticas existentes. Neste sentido, a docência constitui uma das mediações para a construção do discurso de síntese da pedagogia, articulada intrinsecamente com a pesquisa. Assim, a relação docência-pesquisa é um princípio epistemológico da prática.

Destarte, a partir do horizonte vislumbrado para a formação do profissional da educação no curso de pedagogia, as Diretrizes Curriculares Nacionais definem os pilares e os contornos dessa formação:

A educação do licenciado em pedagogia deve, pois, propiciar, por meio de investigação, reflexão crítica e experiência no planejamento, execução, avaliação de atividades educativas, a aplicação de contribuições de campos de conhecimentos, como o filosófico, o histórico, o antropológico, o ambiental-ecológico, o psicológico, o lingüístico, o sociológico, o político, o econômico, o cultural. O propósito dos estudos destes campos é nortear a observação, análise, execução e avaliação do ato docente e de suas repercussões ou não em aprendizagens, bem como orientar práticas de gestão de processos educativos escolares e não-escolares, além da organização, funcionamento e avaliação de sistemas e de estabelecimentos de ensino. (Parecer CNE/CP n. 05/2005, p. 6)

Como se depreende, a perspectiva que se apresenta para o curso de pedagogia é de uma formação que favoreça a compreensão da complexidade da escola e de sua organização; que propicie a investigação no campo educacional e, particularmente, da gestão da educação em diferentes níveis e contextos. A pesquisa, a produção do conhecimento no campo pedagógico e o estudo das ciências que dão suporte à pedagogia e a própria reflexão sobre a pedagogia como ciência certamente deverão estar presentes no processo formativo a ser desenvolvido nesse curso, concomitantemente ao estudo a respeito da escola, da prática educativa e da gestão educacional. Evidências encontradas nas DCN-Pedagogia, na medida em que no Parecer CNE/CP n. 05/2005 (p. 6-7) está assim indicado:

Para a formação do licenciado em pedagogia é central o conhecimento da escola como uma organização complexa que tem a função social e formativa de promover, com eqüidade, educação para e na cidadania. (...) Também é central, para essa formação, a proposição, realização, análise de pesquisas e a aplicação de resultados, em perspectiva histórica, cultural, política, ideológica e teórica, com a finalidade, entre outras, de identificar e gerir, em práticas educativas, elementos mantenedores, transformadores, geradores de relações sociais e étnico-raciais que fortalecem ou 
Diretrizes curriculares do curso de pedagogia no Brasil...

enfraquecem identidades, reproduzem ou criam novas relaçôes de poder (...). Finalmente é central a participação na gestão de processos educativos, na organização e funcionamento de sistemas e de instituições de ensino, com a perspectiva de uma organização democrática, em que a coresponsabilidade e a colaboração são os constituintes maiores das relaçôes de trabalho e do poder coletivo e institucional, com vistas a garantir iguais direitos, reconhecimento e valorização das diferentes dimensões que compõem a diversidade da sociedade, assegurando comunicação, discussão, crítica, propostas dos diferentes segmentos das instituiçôes educacionais escolares e não-escolares.

A formação proposta para o profissional da educação do curso de pedagogia é abrangente e exigirá uma nova concepção da educação, da escola, da pedagogia, da docência, da licenciatura. Uma nova compreensão que situe a educação, a escola, a pedagogia, a docência, a licenciatura no contexto mais amplo das práticas sociais construídas no processo de vida real dos homens, com o fim de demarcar o caráter sócio-histórico desses elementos.

O curso de pedagogia define-se como um curso de licenciatura e, neste sentido, o mencionado Parecer explicita que a formação para o exercício da docência nas áreas especificadas constitui um de seus pilares. Em contrapartida, ao se compreender e definir o curso de pedagogia como uma licenciatura, não se pode incorrer no equívoco de organizá-lo curricularmente como um curso circunscrito ao campo das metodologias de ensino e dos conteúdos relativos aos saberes específicos para o exercício da docência na educação infantil, nos anos iniciais do ensino fundamental, no curso da modalidade normal no ensino médio ou, ainda, nos cursos de formação profissional na área da educação que começam a se fazer presentes em nossa realidade. Até mesmo porque, como já se destacou, também, em outros momentos, o exercício da docência desenvolve-se no contexto mais amplo da educação, da escola e da própria sociedade, e, sendo assim, a formação para tal exercício profissional deve fornecer elementos para o domínio desse contexto.

A compreensão da licenciatura nos termos das DCN-Pedagogia implicará, pois, uma sólida formação teórica, alicerçada no estudo das práticas educativas escolares e não-escolares e no desenvolvimento do pensamento crítico, reflexivo fundamentado na contribuição das diferentes ciências e dos campos de saberes que atravessam o campo da pedagogia. Essa sólida formação teórica, por sua vez, exigirá novas formas 
de se pensar o currículo e sua organização, para além daquelas concepçōes fragmentadas, parcelares, restritas a um elenco de disciplinas fechadas em seus campos de conhecimento. Ao contrário, as DCN-Pedagogia apontam para uma organização curricular fundamentada nos "princípios de interdisciplinaridade, contextualização, democratização, pertinência e relevância social, ética e sensibilidade afetiva e estética" (p. 1).

Desse modo, os núcleos que definirão a estrutura do curso de pedagogia - núcleo de estudos básicos; núcleo de aprofundamento e diversificação de estudos; núcleo de estudos integradores - devem se integrar e articular ao longo de toda a formação, a partir do diálogo entre os diferentes componentes curriculares, por meio do trabalho coletivo sustentado no princípio interdisciplinar dos diferentes campos científicos e saberes que informam o campo da pedagogia.

Por sua vez, a formação para a gestão educacional, como indicada nas DCN-Pedagogia, traz uma contribuição importante rompendo com visōes fragmentadas e fortemente centralizadas da organização escolar e dos sistemas de ensino. Nos debates sobre a formação do pedagogo vários estudos evidenciaram como a divisão do curso de pedagogia em habilitações, como preconizado no Parecer CFE/CP n. 262/1969, acabou por contribuir para que se instalassem, na organização dos processos de trabalho na escola e nos sistemas de ensino, modelos caracterizados pela divisão pormenorizada do trabalho educativo; pela dicotomização das funções de planejamento, concepção, controle e avaliação, de um lado e, do outro, das funções de implementação, de realização do trabalho planejado; pela reprodução de estruturas e práticas de poder excludentes, também, no contexto das práticas educativas.

Por certo, esses modelos de organização da educação não são determinados apenas pela formação desenvolvida nos cursos que formam profissionais da educação, mais especificamente, nos cursos de pedagogia. No entanto, essa formação desempenha um papel importante na produção das condições históricas para a manutenção ou superação desses modelos, e, neste sentido, contribuindo para a afirmação da gestão democrática da educação como elemento central na direção dessa superação.

Ao se indicar o campo de atuação do licenciado em pedagogia, as DCN-Pedagogia compreendem, assim, a gestão educacional:

Gestão educacional, entendida numa perspectiva democrática, que integre as diversas atuações e funções do trabalho pedagógico e de processos

Educ. Soc., Campinas, vol. 27, n. 96 - Especial, p. 819-842, out. 2006 
Diretrizes curriculares do curso de pedagogia no Brasil...

educativos escolares e não-escolares, especialmente no que se refere ao planejamento, à administração, à coordenação, ao acompanhamento, à avaliação de planos e de projetos pedagógicos, bem como análise, formulação, implementação, acompanhamento e avaliação de políticas públicas e institucionais na área de educação. (Parecer CNE/CP n. 05/2005, p. 8)

Definida nestes termos, superam-se de maneira definitiva aqueles modelos de organização curricular estruturados para formação por "habilitação", que culminavam na formação dos denominados "especialistas em educação", como o supervisor, o orientador, o administrador, o inspetor educacional, entre outros. Eis como essa questão fica definida no artigo 14 da Resolução CNE/CP n. 01/2006:

Art. 14. A Licenciatura em pedagogia, nos termos dos Pareceres CNE/CP n. 5/2005 e n. 3/2006 e desta Resolução, assegura a formação de profissionais da educação prevista no art. 64, em conformidade com o inciso VIII do art. $3^{\circ}$ da Lei n. 9.394/96.

$\$ 1^{\circ}$ Esta formação profissional também poderá ser realizada em cursos de pós-graduação, especialmente estruturados para este fim e abertos a todos os licenciados.

$\$ 2^{\circ}$ Os cursos de pós-graduação indicados no $₫ 1^{\circ}$ deste artigo poderão ser complementarmente disciplinados pelos respectivos sistemas de ensino, nos termos do parágrafo único do art. 67 da Lei n. 9.394/96.

E o Parecer CNE/CP n. 3/2006 esclarece de forma mais definitiva as dúvidas sobre a eventual observância do disposto no artigo 64 da Lei n. 9.394/1996, ao enfatizar, de um lado, que a licenciatura em pedagogia, realiza a formação para administração, planejamento, inspeção, supervisão e orientação educacional, em organizações (escolas e órgãos dos sistemas de ensino) da educação básica e, de outro lado, estabelece as condições em que a formação pós-graduada para tal deve ser efetivada. Desse modo, o Parecer reitera a concepção de que a formação dos profissionais da educação, para funções próprias do magistério e outras, deve ser baseada no princípio da gestão democrática (obrigatória no ensino público, conforme a CF, art. 206-VI; LDB, art. $3^{\circ}-$ VIII) e superar aquelas vinculadas ao trabalho em estruturas hierárquicas e burocráticas.

Tal posicionamento ainda é justificado pelo Parecer CNE/CP n. 5/ 2005 que, ao considerar o caráter colegiado da organização escolar, prevê que todos os licenciados possam ter oportunidade de ulterior aprofundamento da formação pertinente, ao longo de sua vida profissional. Su- 
pera, assim, a interpretação baseada em legislação anterior (Lei n. 5.540/1968 e currículos mínimos) que restringia a formação para as funções já mencionadas aos licenciados de pedagogia. A propósito dessa questão, o Conselho designou comissão para emitir parecer sobre diretrizes para a formação dos profissionais da educação com relação aos artigos 64 e 67, parágrafo único, da Lei n. 9.394/96.

Certamente, um desafio que fica para os educadores brasileiros é se articularem para uma intervenção efetiva na definição das orientações que regerão a formação a ser desenvolvida nos cursos de pós-graduação destinados à "formação dos profissionais para administração, planejamento, inspeção, supervisão e orientação na educação básica", de modo que venha a contribuir, igualmente, para o fortalecimento da gestão democrática da educação e da escola e a construção de uma educação pública de qualidade.

\section{Novos e maiores desafios para o campo da formação}

Outras questões também estão no horizonte das modificações necessárias no âmbito da formação dos educadores profissionais da educação, entre as quais podemos destacar a inclusão, no texto da Lei da Reforma do Ensino Superior, do papel da universidade e das faculdades, dos centros de educação e departamentos de educação, na formação dos educadores, professores e profissionais para a educação básica; a revisão urgente da LDB (artigo 64) e da Resolução n. 01/99, no que tange à criação dos ISEs e do Curso Normal Superior, como condição para a instituição de um sistema orgânico de formação de professores no país; revisão das Diretrizes Curriculares para a Formação Inicial de Professores da Educação Básica.

Considerando ainda o grande número de ISEs e Cursos Normais Superiores criados nos últimos anos, bem como de cursos especiais de formação, tanto no âmbito da iniciativa privada como no âmbito de instituiçôes públicas, é fundamental a definição de procedimentos que garantam de imediato:

- O desenvolvimento de processos de avaliação institucional, que antecedam a processos de reconhecimento e criação de novos processos de autorização para tais cursos/instituiçóes e que considerem condições efetivas de realização das ativida- 
Diretrizes curriculares do curso de pedagogia no Brasil...

des propostas, seja em disciplinas, estágios ou atividades complementares etc.

- Um estudo rigoroso do número de vagas ofertadas nessas instituiçôes - principalmente considerando que a grande maioria oferece vagas no período noturno, ao qual acorrem estudantes trabalhadores, nem sempre professores em exercício, impedindo a realização dos estágios e da formação prática e teórica com a qualidade necessária às exigências da educação de crianças, jovens e adultos.

Com a aprovação das Diretrizes, não se extinguem as polêmicas que acompanham as discussóes sobre seu caráter e a identidade do curso de pedagogia. $\mathrm{O}$ enfrentamento dessas questões não é tarefa para uma ou outra entidade, mas desafio para a área da educação, para a investigação e a pesquisa interdisciplinares, compartilhadas a muitas mãos. Outros desafios emergem de sua aprovação, entre eles o principal é o de caminhar na perspectiva de construir efetivamente cursos e percursos de formação no campo da educação e da pedagogia, para formar profissionais que atuarão na educação básica, na formação de crianças, jovens e adultos, na gestão e organização dos espaços escolares e na elaboração de formas criativas e criadoras para a educação escolar e não-escolar.

As perspectivas que se descortinam para a efetivação de uma política global de formação dos educadores, no país, são promissoras. As motivações para o debate e para a vivência de novas e criativas experiências curriculares nos cursos de pedagogia e licenciaturas são elevadas nos meios acadêmicos. As entidades representativas de importantes segmentos da área - a ANFOPE, o FORUMDIR, a ANPED e o CEDES -, as diretrizes da pedagogia e a política de formação dos profissionais da educação estarão presentes e, certamente, serão objeto de análise e de proposiçôes nos encontros, seminários e congressos que serão realizados no horizonte próximo, com a disposição renovada de firmar, reafirmar e propor, coletivamente, princípios e encaminhamentos que orientarão suas ações concretas.

Tem sido esse o compromisso histórico que pauta a agenda dessas entidades, pois sabem que somente de forma coletiva, solidária e crítica será possível enfrentar aqueles desafios que ainda não estão ao nosso alcance e na esfera de nossa decisão.

Recebido e aprovado em setembro de 2006. 


\section{Notas}

1. Associação Nacional pela Formação dos Profissionais da Educação (ANFOPE), Associação Nacional de Pós-Graduação e Pesquisa em Educação (ANPED), Centro de Estudos Educação e Sociedade (CEDES), Fórum de Diretores de Faculdades/Centros de Educação das Universidades Públicas Brasileiras (ForUmDir), Associação Nacional de Política e Administração da Educação (ANPAE), entre outras.

2. A respeito dessa discussão, consultar Aguiar e Melo (2005a; 2005b).

3. Proposta de Diretrizes Curriculares de Pedagogia elaborada por uma Comissão de Especialistas de Pedagogia, resultante de ampla consulta às universidades e de consensos construídos com as entidades ANPED, ANFOPE, CEDES, FORUMDIR e ANPAE, em 1999.

4. A presença de cerca de 200 pessoas, que representavam a maioria dos estados brasileiros, no painel sobre a Reformulação do Currículo da Pedagogia e das Licenciaturas na I CBE (Anais, 1980, p. 209-217), comprova que em muitos estados germinava a idéia de organização dos educadores em torno dessas reformulaçōes (cf. detalhes em Brzezinski, 1994).

5. Consultar <www.mec.gov.br>.

6. O único documento disponível e não aprovado data de maio de 2000 .

7. Realizado em Águas de Lindóia, São Paulo.

8. Disponível em: <www.mec.gov.br>.

9. Consultar <www. mec.gov.br/cne>.

10. Conferir <www.mec.gov.br/cne>.

11. Estes documentos podem ser encontrados no site da ANFOPE: <http://lite.fae.unicamp.br/ anfopes.

12. Aprovada no CEE-SP a Indicação n. 22/2002, que estabelece distinção entre os cursos de pedagogia licenciaturas e pedagogia bacharelado, dando cumprimento ao estabelecido no artigo $64 \mathrm{da}$ LDB.

\section{Referências bibliográficas}

AGUIAR, M.A.S. A formação do profissional da educação no contexto da reforma educacional brasileira. In: FerReira, N.S.C. (Org.). Supervisão educacional para uma escola de qualidade. São Paulo: Cortez, 1999.

AGUIAR, M.A.S. Os institutos superiores de educação: uma das faces da reforma no Brasil. In: SGUISSARDI, V. (Org.). Educação superior: velhos e novos desafios. São Paulo: Xamã, 2000.

AGUIAR, M.A.S. Espaço da gestão na formação do profissional da educação. In: Ferreira, N.S.C.; MAChado, L.M. Politica e gestão da educação: dois olhares. Rio de Janeiro: DP\&A, 2002. 
Diretrizes curriculares do curso de pedagogia no Brasil...

AGUIAR, M.A.S. A formação dos profissionais da educação básica no curso de pedagogia. In: Ferreira, N.S.C.; Aguiar, M.A.S. (Org.). Para onde vão a orientação e a supervisão educacional. 2. ed. Campinas: Papirus, 2002.

AGUIAR, M.A.S.; MELO, M.M.O. Pedagogia e as diretrizes curriculares do curso de pedagogia: polêmicas e controvérsias. Revista Linhas Críticas, Brasília, DF, v. 11, 2005a.

AGUIAR, M.A.S.; MELO, M.M.O. Pedagogia e faculdades de educação: vicissitudes e possibilidades da formação pedagógica e docente nas IFES. Educação \& Sociedade, Campinas, v. 26, n. 92, p. 959-982, out. 2005b.

ALVES, N. Trajetórias e redes na formação de professores. Rio de Janeiro: DP\&A, 1998.

ANDRÉ, M. Uma pesquisa com os professores para avaliar a formação de professores. In: RomanowsKi, J.P. et al. (Org.). Conhecimento local e conhecimento universal: pesquisa, didática e ação docente. Curitiba: Champagnat, 2004.

ASSOCIAÇÃO NACIONAL PELA FORMAÇÃO DOS PROFISSIONAIS DA EDUCAÇÃO (ANFOPE). O profissional do ensino: debates sobre a sua formação. Cadernos CEDES, Campinas, n. 17, 1986.

ASSOCIAÇÃO NACIONAL PELA FORMAÇÃO DOS PROFISSIONAIS DA EDUCAÇÃO (ANFOPE). In: ENCONTRO NACIONAL DA ANFOPE, 9., 1998, Campinas, sp. Documento final. Campinas, SP, 1998.

ASSOCIAÇÃO NACIONAL PELA FORMAÇÃO DOS PROFISSIONAIS DA EDUCAÇÃO (ANFOPE). Políticas públicas de formação dos profissionais da educação: desafios para as instituições de ensino superior. In: ENCONTRO NACIONAL DA ANFOPE, 12., 2004, Brasília, DF. Documento final. Brasília, DF, 2004.

ANTUNHA, H.C.G. As origens da Faculdade de Educação da USP: a introdução de estudos pedagógicos em nível superior no estado de São Paulo. Revista da Faculdade de Educação da USP, São Paulo, v. 1, n. 1, p. 25-41, 1975.

BRASIL. Ministério da Educação. Secretaria de Educação Superior. Comissão de Especialistas do Curso de Pedagogia. Proposta de diretrizes curriculares 
para o curso de pedagogia. Brasília, DF: MEC/SESU, 1999. Disponível em: $<$ http//:www.mec.gov.br/sesu/diretriz.htm>. Acesso em: 1 maio 2005.

BRZEZINSKI, I. Pedagogia, pedagogos e formação de professores: busca e movimento. 1994. Tese (Doutorado) - Universidade de São Paulo, São Paulo.

BRZEZINSKI, I. Diretrizes curriculares para o curso de pedagogia. In: SEMINÁRIO NACIONAL SOBRE FORMAÇÃO DE PROFISSIONAIS DE EDUCAÇÃO, 7., 2005, Brasília, DF. (texto impresso por meios eletrônicos)

BRZEZINSKI, I. Pedagogia, pedagogos e formação de professores: busca e movimento. 5. ed. Campinas: Papirus, 2005.

BRZEZINSKI, I. Políticas de formação de pedagogos e as novas Diretrizes Curriculares Nacionais: embates, contradiçôes e açōes. In: ENCONTRO DE PESQUISA EM EDUCAÇÃO DA REGIÄO CENTRO-OESTE/ ANPED, 8., 2006, Cuiabá. (no prelo).

CHAGAS, V. Estudos pedagógicos superiores: Parecer n. 252/69. Documenta, Rio de Janeiro, n. 100, p. 101-112, 1969.

CHAGAS, V. Resolução do CFE que dispõe sobre o preparo dos especialistas e professores de educação. Didata, São Paulo, n. 5, p. 5-22, 1976.

CHAGAS, V. Formação do magistério: novo sistema. São Paulo: Atlas, 1976.

ENCONTRO NACIONAL DA COMISSÃO NACIONAL DE REFORMULAÇÃO DOS CURSOS DE FORMAÇÃO DOS EDUCADORES (CONARCFE), 3., 1988, Brasília, DF. Documento final. Brasília, DF: CONARCFE, 1988.

ENCONTRO NACIONAL DO PROJETO DE REFORMULAÇÃO DOS CURSOS DE PREPARAÇÃO DE RECURSOS HUMAN̉OS PARA A EDUCAÇÃO, 1., 1983, Belo Horizonte. Documento final. Belo Horizonte: CONARCFE, 1983. (impresso por meios eletrônicos)

FERNANDES, F. Formação de profissionais especialistas nas faculdades de filosofia. Revista Brasileira de Estudos Pedagógicos, Rio de Janeiro, v. 37, n. 85, p. 227-233, jan./mar. 1962.

FORUM DE DIRETORES DAS FACULDADES DE EDUCAÇÃO DAS UNIVERSIDADES PUBLICAS BRASILEIRAS (FORUMDIR).

Educ. Soc., Campinas, vol. 27, n. 96 - Especial, p. 819-842, out. 2006 
Diretrizes curriculares do curso de pedagogia no Brasil...

Considerações do FORUMDIR sobre o Projeto de Resolução que institui Diretrizes Curriculares Nacionais para os Cursos de Graduação em Pedagogia do Conselho Nacional de Educação. Brasília, DF, 2005.

FREITAS, H.C.L. O trabalho como princípio articulador na prática de ensino e nos estágios. Campinas: Papirus, 1996.

FREITAS, H.C.L. A formação inicial e continuada dos profissionais da educação. In: Aguiar, M.A.S.; Silva, A.M.M. Retrato da escola no Brasil. Brasília, DF: CNTE, 2004.

FREITAS, L.C. Notas sobre a especificidade do pedagogo e sua responsabilidade no estudo da teoria e da prática pedagógica. Educação \& Sociedade, Campinas, v. 7, n. 22, p. 12-19, 1985.

FREITAS, L.C. Projeto histórico, ciência pedagógica e didática. Educação \& Sociedade, São Paulo, v. 9, n. 27, p. 122-140, 1987.

FREITAS, L.C. Neotecnicismo e formação do educador. In: ALVES, N. (Org.). Formação de professores: pensar e fazer. São Paulo: Cortez, 1992.

GADOTTI, M.; PINO, I.R. A redefinição do curso de pedagogia: idéias diretrizes. Revista Brasileira de Estudos Pedagógicos, Brasília, DF, v. 63, n. 144, p. 59-66, mai./ago. 1979.

KUENZER, A.Z. As políticas de formação: a construção de identidade do professor sobrante. Educação \& Sociedade, Campinas, v. 20, n. 68, p.163-183, 1999.

LIBÂNEO, J.C. Pedagogia e pedagogos, para quê? São Paulo: Cortez, 1999.

MELO, M.M.O. A construção do saber docente: entre a formação e o trabalho. 2000. Tese (Doutorado) - Faculdade de Educação, Universidade de São Paulo, São Paulo.

MELO, M.M.O. O currículo da educação básica no contexto de crises da sociedade. Revista de Educação AEC, Brasília, DF, n. 129, 2003.

MELO, M.M.O. Pedagogia e curso de pedagogia: riscos e possibilidades epistemológicos face ao debate e às novas Diretrizes Curriculares Nacionais sobre esse curso. In: ENCONTRO NACIONAL DE 
DIDATICA E PRATICA DE ENSINO, 13., 2006, Recife. Anais... Recife: ENDIPE, 2006.

MOREIRA, A.F.; GARCIA, R.L. Começando uma conversa sobre currículo. In: Moreira, A.F.; GARCIA, R.L. Currículo na contemporaneidade: incertezas e desafios. São Paulo: Cortez, 2003.

MORIN, E. Ciência com consciência. Lisboa: Europa-América, 1990.

PIMENTA, S.G. Formação de profissionais da educação: visão crítica e perspectivas de mudança. In: Pimenta, S.G.; Libâneo, J.C. (Org.). Pedagogia e pedagogos: caminhos e perspectivas. São Paulo: Cortez, 2002.

SACRISTAN, G.J. Pós-modernidade: a lógica cultural do capitalismo tardio. São Paulo: Ática, 1996.

SANTOMÉ, J.T. Globalização e interdisciplinaridade: o currículo integrado. Porto Alegre: Artes Médicas, 1998.

SANTOS, B.S. Um discurso sobre as ciências na transição para uma ciência pós-moderna. Estudos Avançados, São Paulo, v. 2, n. 2, p. 56-71, mai./ago. 1988.

SANTOS, L.L.C.P. Globalização, multiculturalismo e currículo. In: Moreira, A.F.B. (Org.). Currículo: questōes atuais. São Paulo: Papirus, 1997.

SAVIANI, D. Educação e questôes da atualidade. São Paulo: Cortez, 1991.

SCHEIBE, L.; AGUIAR, M.A.S. Formação de profissionais da educação no Brasil: o curso de pedagogia em questão. Educação \& Sociedade, Campinas, v. 20, n. 68, p. 220-238, 1999.

SEMINÁRIO NACIONAL SOBRE A FORMAÇÃO DOS PROFISSIONAIS DA EDUCAÇÃO., 7., 2005, Brasília, DF. Documento final. Brasília, DF: ANFOPE, 2005. (impresso por meios eletrônicos).

SILVA, C.S.B. Curso de pedagogia no Brasil: história e identidade. Campinas: Autores Associados, 1999.

TARDIF, M. Saberes docentes e formação profissional. Petrópolis: Vozes, 2002.

Educ. Soc., Campinas, vol. 27, n. 96 - Especial, p. 819-842, out. 2006 
Diretrizes curriculares do curso de pedagogia no Brasil...

WEBER, S. Como e onde formar professores: um espaço de disputa e confronto. Educação \& Sociedade, Campinas, v. 21, n. 70, p. 129-156, abr. 2000 .

WEBER, S. Profissionalização docente e políticas públicas no Brasil. Educação \& Sociedade, Campinas, v. 24, n. 85, p. 1125-1154, dez. 2003.

ZABALA, A. Enfoque globalizador e pensamento complexo: uma proposta para o currículo escolar. Porto Alegre: Artes Médicas, 2002. 